\title{
Job dissatisfaction and migration: evidence from Tajikistan
}

Ilhom Abdulloev ${ }^{1,2}$ [D

Correspondence:

ailhom@hotmail.com

Open Society Institute Assistance

Foundation - Tajikistan, Dushanbe, Tajikistan

${ }^{2}$ Research Fellow, IZA Institute of Labor Economics, Bonn, Germany

\begin{abstract}
Having a family member migrant reduces not only the labor force participation but also the job satisfaction of those left behind. Migrants' relatives build their expectations on earnings from migration through received information on the wage distribution in the destination country either from the size of remittances or directly from migrants. If their expected earnings from migration greatly exceed their current wages in the source country, migrant relatives become more dissatisfied with their jobs. Using a simple economic model of job satisfaction and applying both parametric and semiparametric estimations to Tajikistan's data, as well as with controlling for an endogeneity issue with the variable of interest, we estimate the significantly positive effect of the difference of the expected outside country earnings and current earnings of migrants' relatives on their job dissatisfaction. A larger gap between what an individual could earn in the migration destination country and what she receives now at her current job in the source country makes that individual unhappier.
\end{abstract}

JEL Classification: F22, F24, J28, 015

Keywords: Job satisfaction, Migration, Remittances, Tajikistan

\section{Introduction}

Our focus in studying the employment-migration relationship is on the source country. We look at how the migration of one person to another (destination) country impacts the labor supply decisions of his relatives who remain in a source country. While all previous studies looked at the effect of remittances on the labor supply decisions of migrant relatives, in this paper, we examine how the outmigration affects the job satisfaction of non-migrating relatives.

Studying the effect of migration on the labor supply is not new. The pioneering work on the effect of migration on labor supply of non-migrant family members is by Rodriguez and Tiongson (2001). They find a negative effect of remittances on the labor supply of the migrants' family members in urban Philippines: an additional US $\$ 40$ of remittances per migrant family member decreases male and female labor participation by $0.3 \%$ and $0.2 \%$, respectively. Subsequent papers find further evidence of this negative effect of remittances on the labor supply. For example, Acosta (2006) finds that remittances received from international migrants reduce the likelihood of labor supply by children and women in migrants' families in El Salvador. Kim (2007) also finds the

(C) The Author(s). 2018 Open Access This article is distributed under the terms of the Creative Commons Attribution 4.0 International License (http://creativecommons.org/licenses/by/4.0/), which permits unrestricted use, distribution, and reproduction in any medium, provided you give appropriate credit to the original author(s) and the source, provide a link to the Creative Commons license, and indicate if changes were made. 
negative effect of remittances on the labor supply at both the individual and geographical cluster levels in Jamaica. Nguyen and Purnamasari (2011) study the Indonesian data and find that migrant family members work $26 \mathrm{~h}$ less per week than members of households without migrants; if the migrant is male, his family members work $33 \mathrm{~h}$ less than the members of non-migrant households. Amuedo-Dorantes and Pozo (2006) reported that a 100 Peso remittance increase would reduce male formal sector employment by $32 \mathrm{~h}$ per month in both urban and rural areas of Mexico, male self-employment by $11 \mathrm{~h}$ per month in urban areas, female nonpaid employment by $6 \mathrm{~h}$ per month, and female informal sector employment by $12 \mathrm{~h}$ per month. Cabegin (2006) studies migration from the Philippines, finding in families with wife migrants that an annual increase in wives' earnings by 10,000 Pesos decreases the likelihood of having the full-time paid employment of their husbands by $12 \%$ more than men in non-migrant families. The same increase also leads to a rise in the likelihood of husbands being unemployed by $6 \%$. In families with husband migrants, the same size increase in husbands' earnings reduces the likelihood of full employment by their wives by $4 \%$ relatively to those in non-migrant households.

Why do remittances negatively affect individual labor supply decisions? Since remittances received from the migrant might have the same effect as that of the non-wage income in the individual (or family) utility maximization problem, there are two possible outcomes. Firstly, remittances could result in an interior solution in the labor supply problem, where the marginal rate of substitution between the consumption and leisure is equal to the real wage rate. Under this condition, if leisure is a normal good, then the increase in non-wage income reduces hours of work of migrant family members. Secondly, remittances might result in a corner solution to the labor supply problem when the marginal rate of substitution of consumption and leisure is greater than the wage rate. Since non-wage income raises individual budget constraints, it also increases individual reservation wages. Once individual reservation wages are increased to such level that they are higher than market wages, migrant family members would choose not to work (for detailed discussion of the effect of the non-wage income on the labor supply, see Killingsworth (1983)).

However, as Rodriguez and Tiongson (2001) stated, it is not entirely clear "whether migrants' remittances have a similar effect on labor supply as other nonlabor income" (p. 721). Due to the complexity of migration process, there are different attributes that along with remittances influence labor supply decisions of migrant family members. Several authors discuss these indirect effects of remittances and migration. Acosta (2006) mentions that the absence of the migrant along with the inflow of remittances might create positive externalities for neighbors of migrant families by relaxing the financial constraints they face as the migrant's family hires neighbors to do some work in their household to compensate migrant's absence. Kim (2007) hypothesizes that remittances are hurting Jamaica's competitiveness in international market by increasing domestic wages. Nguyen and Purnamasari (2011) argued that remittances might affect labor supply of migrant family members differently depending on both migrant's gender and his or her influence on household decisions. Amuedo-Dorantes and Pozo (2006) stated that remittances help men to forego benefits of formal jobs and choose to do informal work. The absence of the husband because of migration would induce women 
with school-age children in remittance-receiving families to leave the full-time employment (Cabegin 2006).

We look at another dimension in studying the effect of migration on the labor supply of migrants' family members in the source country-their job satisfaction. Migrant's family members might consider remittances as their lost earning opportunities from not joining their migrant relatives in working abroad. A non-migrating member of a migrant's family would compare her own current earnings from working in the source country to what she might earn from migration basing on observed remittances from her migrant relatives. Additionally, a current or returning migrant provides information on existing labor market opportunities in the destination country. Using this information, a non-migrating member would create her own expectation on earnings from migration like if she joined the migrant, and compare them to her current wage. Then, the larger the difference between that what she receives now and her expected earnings from migration is, more dissatisfied from her current job she would be.

Individual expectations on earnings from migration might be affected by costs of migration, which are uncertain. Members of migrant families, however, have advantages in reducing such costs basing on their migration experience. First of all, the cost of acquiring information on earnings possibilities in the destination country and on the job search would be lower for migrants' relatives because they learn this information from the migrants' experience. Migration costs are also lowered once the non-migrating members receive help from their migrant relatives in searching for jobs, housing, and fulfilling all working and staying formalities in the destination country when they decide to migrate. Therefore, since the family is involved in migration, its members know how to reduce migration-related costs, which allow them to get earnings almost close to their expected values.

A similar process is observed in our chosen country case, Tajikistan, with respect to its main migration destination country, Russia. Wages in these countries during Soviet period, when the common market existed, were closer to each other. Schroeder (1981) noted that there were no big differences in average wages of state employees among the Soviet Republics in 1960-1978. Wages in these two former Soviet countries started moving away from each other in early 1980s and accelerated after the collapse of the Soviet Union. Current developments in restricting the free movement of people such as the introduction of migrant quotas, and then work patents, also contributed to speeding up the wage divergence between these countries. Figure 1 shows the scale of the accelerating divergence of Tajik real wages from Russian real wages after the collapse of the Soviet Union. The gap between the average real wages in Russia and Tajikistan increased from 3335 Rubles in 2002 to 18,600 Rubles by August 2010. In August 2010, the average real wages in Russian Federation were about 8.5 times higher than those in Tajikistan (Statistical Committee of CIS 2011; State Statistical Agency of Tajikistan 2011; Russian State Statistical Committee 2010). Such differences in wages resulted in increasing seasonal labor migration from Tajikistan to Russia, which might be positively related with increasing job quits in Tajikistan.

Our discussion is consistent with the job satisfaction literature, which defines job satisfaction as an increasing function of the deviation of current workers' wages from the expected wages which they might receive from another employer or occupation. Introduced into the economics literature by Hamermesh (1977), in his economic model, 


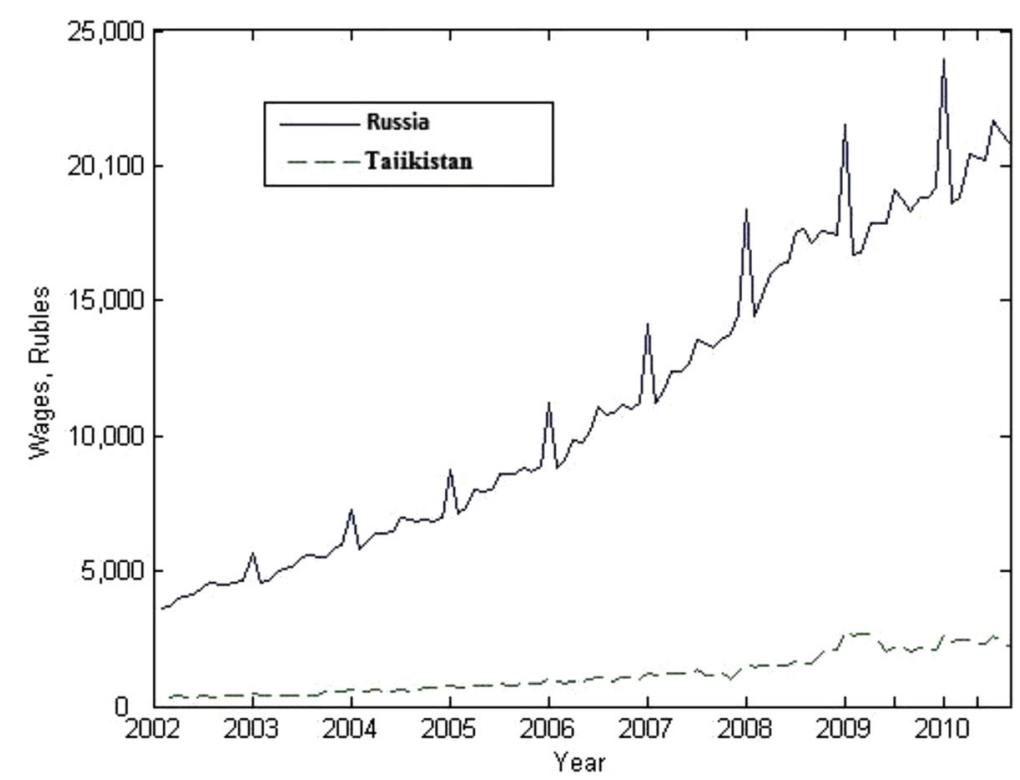

Fig. 1 Comparison of real wages between Russia and Tajikistan, Rubles. Data sources: (1) Data on wages and consumer price index in Tajikistan are from the website of the State Statistical Agency of Tajikistan (State Statistical Agency of Tajikistan 2011). (2) Data on wages and consumer price index in Russia are from Russian State Statistical Committee Monthly Reports on Social and Economic Conditions of Russian Federation (Russian State Statistical Committee 2010). (3) Exchange rates used in converting Tajikistan's wages to Russian Rubbles are from the website of the National Bank of Tajikistan (National Bank of Tajikistan 2011)

workers compare their wages in their current occupations with those from other job alternatives. If workers' current wages are higher than those from alternative jobs, they would be more satisfied with current jobs, and vice versa. His equilibrium condition at the time when an individual starts his work at the new occupation implies that there is no differential job satisfaction. Once the working experience with the current employer increases, the worker becomes more certain about her earning abilities that increase her job satisfaction. He finds a positive relationship between job satisfaction and the deviation of actual wages from the expected wages which are derived using information on the mean of the country's wage distribution conditioned on worker's individual characteristics such as experience, age, education, and gender.

Hamermesh's findings have been confirmed across consequent studies. Clark and Oswald (1996) used two distinct variables in their regression analysis, logarithms of current and expected earnings, instead of a single variable of wage residuals. They found that while the coefficient on the logarithm of current earnings is positive, the coefficient on the logarithm of expected income from other job alternatives is negative and statistically significantly different from zero. Comparison with alternative specifications allowed them to conclude that individual well-being does not depend on absolute income, but on the income comparison, i.e., on the relationship between what a person gets now and what she probably could get if she changed her job. In his following paper, Hamermesh (2001) finds that current shocks which widen earnings inequality also increase the current job satisfaction of those who are at the top of earning distribution. Diaz-Serrano and Vieira (2005) by analyzing European data found that the low-paid workers are less satisfied with their jobs compared to higher paid workers, except the British as they receive larger compensating non-pecuniary benefits. Card et al. 
(2010) using a randomized manipulation of access to information among employees of the University of California find that granting access to earnings information of other employees increases job dissatisfaction among workers with wages less than the median in their pay unit and the same occupations.

Another group of studies have found a significant negative relationship of job satisfaction with job quits. Freeman (1978) in studying the US panel data finds a negative relationship between job quit and job satisfaction: people who are satisfied with their jobs remain with their current employers. Clark et al. (1998) using ten waves of panel data find the same negative relationship between job satisfaction and job quit. Union membership does not affect workers' job satisfaction and decisions: members who are dissatisfied from their jobs are likely to quit as non-members (Clark 2001). Kristensen and Westergaard-Nielsen (2006) found that satisfaction with type of work has more significant impact on choice to quit relatively to other components of job satisfaction. Bockerman and Ilmakunnas (2009) noted that the job dissatisfaction firstly induces job search which in its turn leads to actual job switches.

Jobs satisfaction is also correlated with the subjective well-being (Tait et al. 1989). This relationship is reciprocal and bidirectional, where job and life experiences of the worker affect each other (Judge and Watanabe 1993). The relationship is positive implying that the satisfied worker from his job is feeling being satisfied from other aspects of his life (Rice et al. 1980; Mishra et al. 2014). The relationship of the subjective well-being to job satisfaction is stronger than the causal relationship from job satisfaction to the subjective well-being (Judge and Watanabe 1993; Bowling et al. 2010).

In the next section, we discuss a simple model specification of job satisfaction and incorporate migration into this model. In the third section, we explain the semiparametric ordered response model and discuss how we control for the endogeneity of migration-related variables. The fourth section provides definitions and explanations of the data used in this paper. We used the data from 2007 Living Standard Survey on Tajikistan (State Statistical Agency of Tajikistan 2007), a small Central Asian, former Soviet and transitional country which is highly dependent on migration and remittances. Differences in wages in Tajikistan and its migration destination country, Russia, along with increasing migration, make it a good country case for our study. This section also discusses estimation results of migration on the job satisfaction in Tajikistan. The final, fifth, section concludes.

\section{Model specifications}

\subsection{Simple model of job satisfaction}

We assume that an individual $i$ faces the following utility maximization problem with a constrained amount of leisure:

$$
\max _{\{\mathrm{c}\}} U^{i}\left(c^{i}, \bar{l}^{i}\right)
$$

subject to the budget constraint: 


$$
w^{i}\left(T-\bar{l}^{i}\right)+v^{i} \geq \sum_{j=1}^{n} p_{j} c_{j}^{i}
$$

where $c_{j}^{i}$ is a consumption of good $j$ with corresponding price $p_{j}, c^{i}$ is individual $i$ 's choice of the consumption bundle, $\bar{l}$ is the constrained amount of leisure, $T$ is the total available time, $w^{i}$ is the wage rate, and $v^{i}$ is a non-wage income. Assume also that standard conditions for the utility function along with Inada condition hold, i.e., $U_{c}>0$, $U_{c c}<0$, and $\lim _{c \rightarrow 0} U_{c}=\infty$, respectively.

Killingsworth (1983) defines three main situations when such constrained leisure exists. Firstly, many firms for production efficiency set fixed hours of work and organize workers in several group-shifts. Then, a person has the option either to take the job with the offered fixed hours of work or leave it. Secondly, person-specific factors such as health issues might prevent workers from working more hours than some fixed number of hours. Finally, unemployment caused by imperfect information and imperfect mobility of people results in a discontinuous budget constraint. In such a case, individuals may not be able to immediately take up offers. This sets an upper limit to working hours per period, beyond which the budget becomes discontinuous. In all these situations, the income and substitution effects have little or no impact on individual labor supply decisions. However, one important aspect of such model is that any possible increase in wages would result in increasing individual consumption. To see this, we use Deaton and Muellbauer (1981) results on the linear function of the individual consumption with constrained labor supply.

Deaton and Muellbauer (1981) derived the following linear form of the restricted demand function for the consumption $\operatorname{good} j^{1}$ :

$$
\bar{c}_{j}^{i}=\left(\epsilon_{j}^{i}+\alpha_{j}^{i} \beta^{i}\right)+\left(\frac{\beta_{j}^{i}}{\beta^{i}}-\frac{\theta_{j}^{i}}{\theta^{i}}\right) \beta^{i}\left(\alpha^{i}-\bar{l}^{i}\right)+\left(\frac{\beta_{j}^{i}}{\beta^{i}}+\frac{\alpha_{j}^{i}}{\alpha^{i}-\bar{l}^{i}}\right)\left(w^{i}\left(T^{i}-\bar{l}^{i}\right)+v^{i}-\epsilon^{i}\right),
$$

where $\alpha_{j}^{i}, \alpha^{i}, \beta_{j}^{i}, \beta^{i}, \epsilon_{j}^{i}, \theta_{j}^{i}$, and $\theta^{i}$ are preference parameters from individual $i$ 's utility function.

Notice that an increase in the demand for the consumption good $j$ depends on wages, $w^{i}$, through total income: once the wage increases, it would increase total income available for the individual in such a way that she can spend more in buying the consumption goods. If we assume that there are no changes in individual non-wage income, then for any $w^{i}>w^{i}$ the increment in consumption with constant labor supply can be defined as follows:

$$
\bar{c}_{j}^{\prime i}-\bar{c}_{j}^{i}=\gamma_{j}^{i}\left(w^{\prime i}-w^{i}\right)\left(T-\bar{l}^{i}\right)>0
$$

or, by summing over consumption goods $j$ :

$$
\bar{c}^{i}-\bar{c}^{i}=\gamma^{i}\left(w^{\prime i}-w^{i}\right)\left(T-\bar{l}^{i}\right)>0
$$

where $\bar{c}^{\prime i}=\sum_{j=1}^{n} \bar{c}_{j}^{i}, \bar{c}^{i}=\sum_{j=1}^{n} \bar{c}_{j}^{i}, \gamma_{j}^{i}=\frac{\beta_{j}^{i}}{\beta^{i}}+\frac{\alpha_{j}^{i}}{{ }^{i} \bar{l}^{i}}$, and $\gamma^{i}=\sum_{j=1}^{n} \gamma_{j}^{i}>0$. These expressions are strictly positive since the demand for each consumption good is increasing in wage. 
The last expression shows that the relationship between the expected individual demand for a bundle with more consumption goods and her current consumption can be expressed as the difference in work earnings: if a person wants to increase her consumption, such an increase should be compensated by receiving higher wages.

Next, using the mean value theorem, for any $t^{i} \in(0,1)$, we rewrite the difference between the individual utilities evaluated at $\bar{c}^{i}$ and $\bar{c}^{i}$ in the following form:

$$
\begin{aligned}
U^{i}\left(\bar{c}^{i}, \bar{l}^{i}\right)-U^{i}\left(\bar{c}^{i}, \bar{l}^{i}\right)= & -U_{c}^{i}\left(t^{i} \bar{c}^{i}-\left(1-t^{i}\right) \bar{c}^{\prime}, \bar{l}^{i}\right)\left(\bar{c}^{\prime}-\bar{c}^{i}\right)<0 \\
& =-\rho^{i}\left(w^{\prime}{ }^{i}-w^{i}\right)\left(T-\bar{l}^{i}\right)<0,
\end{aligned}
$$

which is strictly negative due to the imposed condition on utility function, $U_{c}>0$, and $w^{\prime}>w^{i}$, implying $\Delta \bar{c}>0$; and $\rho^{i}$ is a random parameter driven by individual utility parameters for expected wage $w^{\prime}{ }^{i}$,

$$
\rho^{i}=\gamma^{i} U_{c}^{i}\left(t^{i} \bar{c}^{i}-\left(1-t^{i}\right) \bar{c}^{i}, \bar{l}^{i}\right)>0 .
$$

The important result from (1) is that the comparison of utilities received from consuming different amounts of consumption goods could be made based on the difference between wages. The economic interpretation of this result is that, using the available information on the within source country wage distribution, an individual would construct her wage expectation from other possible job alternatives. In such a way, she can evaluate the possible changes in her consumption if she decides to quit her current job in favor of new jobs with different wages. If her wage expectation from outside jobs is higher than her current wage, or equivalently $w^{\prime i}>w^{i}$, then she would be unhappy with her current job. The outside wage is evaluated using the country's internal wage distribution:

$$
w^{\prime i}=\int_{\min w_{A}}^{\infty} w d F_{A}(w),
$$

where $\min w_{A}$ and $F_{A}(w)$ are the minimal wage rate and the wage distribution in the country $A$, respectively.

Notice that in the regression analysis, the expression (1) can be referred to as a random coefficient model, since the parameter $\rho^{i}$ is random over population. The most useful way is to write $\rho^{i}=\bar{\rho}+u^{i}$ with $E(\rho)=\bar{\rho}$ and $E(u)=0$; then, expression (1) can be rewritten as:

$$
\rho^{i}\left(w^{\prime i}-w^{i}\right)\left(T-\bar{l}^{i}\right)=\bar{\rho}\left(w^{\prime i}-w^{i}\right)\left(T-\bar{l}^{i}\right)+\tilde{u}^{i},
$$

where $\tilde{u}^{i}=u^{i}\left(w^{i}-w^{i}\right)\left(T-\bar{l}^{i}\right)$. The final expression has a constant coefficient on the wage differences which is a parameter of interest, as well as the interaction term between the unobserved heterogeneity and wage differences. Therefore, one also needs to calculate the average partial effects of model variables, by averaging over unobserved $\tilde{u}^{i}$.

Using the last expression, we can rewrite the function of job satisfaction. First, notice that an individual would be satisfied if her current wage is greater than that which she might receive from any other employer: $U^{i}\left(\bar{c}^{i}, \bar{l}^{i}\right)-U^{i}\left(\bar{c}^{i}, \bar{l}^{i}\right)>0$. Therefore, an individual would compare her current wage, $w^{i}$, to the possible wage that she could receive in another job, $w^{\prime}{ }^{i}$, for the same hours of work based on her individual worker 
characteristics and current market conditions. Define by $J$ the index of individual $i$ 's job satisfaction; for unknown cut points $\tau_{1}<\tau_{2}<\ldots<\tau_{k-1}$ :

$$
\begin{array}{cc}
J_{1}=1: & \quad \alpha_{w}\left(w^{\prime i}-w^{i}\right)\left(T-\bar{l}^{i}\right)+\tilde{u}^{i} \leq \tau_{1} \\
J_{2}=2: & \tau_{1}<\alpha_{w}\left(w^{\prime}-w^{i}\right)\left(T-\bar{l}^{i}\right)+\tilde{u}^{i} \leq \tau_{2} \\
\vdots & \vdots \\
J_{k}=k: & \tau_{k-1}<\alpha_{w}\left(w^{\prime i}-w^{i}\right)\left(T-\bar{l}^{i}\right)+\tilde{u}^{i}
\end{array}
$$

Using this specification, we can estimate the effect of the difference between the individual expected wages from other jobs and current wages on the job satisfaction. Since by construction $\rho^{i}>0$, current job satisfaction from having lower wages, i.e., increasing wage difference of $\left(w^{\prime i}-w^{i}\right)$, would be a simple $t$ test on the negative sign of the coefficient $\alpha_{w}$.

\subsection{Migration and job satisfaction}

Once a household sends a migrant, its members acquire information about outside country wage distribution through either the size of remittances, or information directly received from a migrant. Having such information, a member $i$ of the migrant's family would construct her expectation on her earnings from migration as if she has migrated:

$$
r^{\prime i}=\int_{\min w_{B}}^{\infty} w d F_{B}(w)
$$

where $\min w_{B}$ and $F_{B}(w)$ are the minimal wage rate and the wage distribution in the destination country $B$, respectively.

Therefore, with such information, she would be able to compare her utility based on her earnings in her source country with her utility from her expected earnings in the destination country:

$$
U^{i}\left(\bar{c}^{i}, \bar{l}^{i}\right)-U^{i}\left(\bar{c}^{r i}, \bar{l}^{i}\right)=-\rho^{i, r}\left(r^{i}-w^{i}\right)\left(T-\bar{l}^{i}\right)=-\bar{\rho}^{r}\left(r^{i}-w^{i}\right)\left(T-\bar{l}^{i}\right)+\tilde{u}^{i, r},
$$

where $r^{i}$ is the expected wage earnings from migration by individual $i, \bar{c}^{r i}$ is an individual $i$ 's target consumption if she migrated, $\tilde{u}^{i, r}=u^{i, r}\left(r^{i}-w^{i}\right)\left(T-\bar{l}^{i}\right)$ is an heteroscedastic error term, and $\bar{\rho}^{r}$ with $\rho^{i, r}$ reflect changes in utility parameters with observed remittances.

Her current job satisfaction depends on two parallel utility comparisons defined as in (1) and (4):

$$
\begin{aligned}
& {\left[U^{i}\left(\bar{c}^{i}, \bar{l}^{i}\right)-U^{i}\left(\bar{c}^{\prime i}, \bar{l}^{i}\right)\right]+\left[U^{i}\left(\bar{c}^{i}, \bar{l}^{i}\right)-U^{i}\left(\bar{c}^{r i}, \bar{l}^{i}\right)\right]} \\
& =-\left(\bar{\rho}\left(w^{\prime}{ }^{i}-w^{i}\right)\left(T-\bar{l}^{i}\right)+\bar{\rho}^{r}\left(r^{i}-w^{i}\right)\left(T-\bar{l}^{i}\right)+\tilde{u}^{i}+\tilde{u}^{i, r}\right)
\end{aligned}
$$

We estimate this equation for migrant family members working in the source country. Notice that we intentionally add both wage differences in the equation, which allow us to estimate the effect of the difference of the expected outside country wages and current wages of migrants' relatives on their job satisfaction keeping constant the difference in the expected internal country wage and current wages. 
Starting from this point, we distinguish these two differences by calling the first difference, i.e., the difference between individual expected wages from internal country jobs and individual's current wages, as the intra-country wage difference. We call the second difference, i.e., the difference between individual expected wages from migration (or the destination country wage distribution) and individual's current wages, as the inter-country wage difference.

One can also interpret the last equation using the definition of first order stochastic dominance. If the destination country's wage distribution dominates the wage distribution in the source country in the sense of the first stochastic dominance, expected utility from migration would be higher than the expected utility of changing jobs within the source country: $F_{B}(w) \leq F_{A}(w)<=>U^{i}\left(\bar{c}^{\prime}, \bar{l}^{i}\right) \leq U^{i}\left(\bar{c}^{r i}, \bar{l}^{i}\right)$. This implies a significant negative effect of the inter-country wage difference, $\left(r^{i}-w^{i}\right)$, on the their job satisfaction. A similar argument works, if one apply the second order stochastic dominance in considering the wage distributions between the source and destination countries for certain occupations or workers' other individual characteristics.

Using this expression, we can rewrite the job satisfaction index function (4) including information on inter-country wage differences of the migrants' relatives:

$$
\begin{array}{cl}
J_{1}=1: & \alpha_{w}\left(w^{\prime i}-w^{i}\right)\left(T-\bar{l}^{i}\right)+\alpha_{r} m^{i, h}\left(r^{i}-w^{i}\right)\left(T-\bar{l}^{i}\right)+\tilde{\zeta}^{i} \leq \tau_{1} \\
J_{2}=2: & \tau_{1}<\alpha_{w}\left(w^{\prime}{ }^{i}-w^{i}\right)\left(T-\bar{l}^{i}\right)+\alpha_{r} m^{i, h}\left(r^{i}-w^{i}\right)\left(T-\bar{l}^{i}\right)+\tilde{\zeta}^{i} \leq \tau_{2} \\
\vdots & \vdots \\
J_{k}=k: & \tau_{k-1}<\alpha_{w}\left(w^{\prime i}-w^{i}\right)\left(T-\bar{l}^{i}\right)+\alpha_{r} m^{i, h}\left(r^{i}-w^{i}\right)\left(T-\bar{l}^{i}\right)+\tilde{\zeta}^{i},
\end{array}
$$

where $m^{i, h}=1$ if the households $h$ of the individual $i$ has any migrant and $\tilde{\zeta}^{i}=-\left(\tilde{u}^{i}\right.$ $\left.+m^{i, h} \tilde{u}^{i, r}\right)$ is a composite heteroscedastic error term. According to our discussions above, $\alpha_{w}$ and $\alpha_{r}$ both should have negative signs.

\section{Econometric model}

\subsection{Semiparametric estimation}

Both models in (3) and (5) imply heteroscedastic error terms $\tilde{u}^{i}$ and $\tilde{u}^{i, r}$. The estimation of such models using standard parametric ordered response models could be problematic. According to Wooldridge (2010), the current concerns in parametric estimation are mainly about the signs of the model coefficients as well as their magnitudes. Firstly, if parametric response models are applied, the heteroscedastic error terms might affect the signs of partial effects of the model variables in such a way that the true coefficients of model variables would have different signs from the partial effects of those variables. Secondly, in parametric ordered models, the signs of estimated coefficients do not necessarily determine the directions of corresponding variable effects on model intermediate outcomes (i.e. for $m=2, \ldots, k-1$ ), because of symmetry and monotonicity properties the standard normal probability distribution function, as well as the size of the cut points. And, finally, the parametric estimation of response models with endogenous variables would produce scaled estimates; thus, to derive the original values of coefficients can be estimated by dividing them by bootstrapped standard errors, or using the delta method.

We use the semiparametric estimation for models (3) and (5), which is based on results from Klein and Spady (1993), Blundell and Powell (2004), and Rothe (2009). The 
main advantage of semiparametric methods in estimating our job satisfaction model is that it allows us to relax the distributional assumptions on the error terms of the model $\tilde{u}^{i}$ and $\tilde{u}^{i, r}$. Such advantage is crucial, since in the parametric model the consistency of estimators is sensitive to the distributional assumption of the error term (Klein \& Sherman, 2002).

Firstly, we impose the single index restriction for probabilities of outcomes of reported job satisfactions $Y_{m}=1$, as in categorical numbers of $m=1,2 \ldots k$, conditional on data $X_{1}, X_{2}, X_{3}$ by

$$
\begin{aligned}
\mathrm{E}\left(Y_{m}=1 \mid X_{1}, X_{2}, X_{3}\right) & =\operatorname{Pr}\left(X_{1} \beta_{1}+X_{2} \beta_{2}+X_{3} \beta_{3}+C_{0}+u \geq 0\right) \\
& =\operatorname{Pr}\left(\beta_{1}\left(X_{1}+X_{2} \theta_{1}+X_{3} \theta_{2}\right)+C_{0}+u \geq 0\right) \\
& =\operatorname{Pr}\left(X_{1}+X_{2} \theta_{1}+X_{3} \theta_{2}+\epsilon \geq 0\right)=\operatorname{Pr}\left(V_{1} \geq-\epsilon\right)=F_{m}\left(V_{1}\right),
\end{aligned}
$$

where $Y_{m}=1\left\{J_{m}=k\right\}, \beta$ 's are original coefficients of the model, $\theta^{\prime} \mathrm{s}$ are ratios of original coefficients to $\beta_{1}, C_{o}$ is the constant of the model, $V_{1}=X_{1}+X_{2} \theta_{1}+X_{3} \theta_{2}$ is an index, $u$ is an error term with $E(u)=0$, and $\epsilon=C_{0}+u, F_{m}$ is the cumulative density function. For identification and consistency purposes, $X_{1}$ should be a continuous variable and there should be no other functions of $X_{1}$ in the model; a matrix $\left(X_{1}, X_{2}, X_{3}, 1\right)$ has a full rank as $N \rightarrow \infty$.

Such restrictions allow us to improve the finite sample behavior of our estimator by keeping the dimension of the data small, to apply estimation even when the index has a non-linearly functional form. This restriction allows estimating a ratio of coefficients ignoring the constant term along with the thresholds. Imposing such restriction, however, do not help us to recover the original coefficients of the model.

Using such index restriction, we would be able to derive the conditional distribution of $Y_{m}$ on model's data $X_{1}, X_{2}, X_{3}$ using the following conditional expectations:

$$
\begin{aligned}
& \mathrm{E}\left(Y_{1}=1 \mid X_{1}, X_{2}, X_{3}\right)=F_{1}\left(V_{1}\right) \\
& \mathrm{E}\left(Y_{2}=1 \mid X_{1}, X_{2}, X_{3}\right)=F_{2}\left(V_{1}\right) \\
& \vdots \\
& \mathrm{E}\left(Y_{m}=1 \mid X_{1}, X_{2}, X_{3}\right)=F_{m}\left(V_{1}\right)
\end{aligned}
$$

Each expectation could be derived using a single-index binary model discussed in Klein and Spady (1993). Hence, using the above probabilities, we can write the quasi loglikelihood function in the following form:

$$
\ln \mathcal{L}=\frac{1}{N} \sum_{i} \sum_{m} \pi_{i} \ln \left(F_{m}\left(V_{1 i}\right)\right)
$$

where $\pi_{i}$ is a trimming function, which helps to keep the probabilities away from the end of tails, and $N$ is a sample size.

These probabilities can be estimated using the kernel regression estimator

$$
\hat{F}_{m}\left(\hat{V}_{1 i}\right)=\frac{\sum_{j \neq i} Y_{m, i} K\left(\frac{\hat{V}_{1 i}-\hat{V}_{1 j}}{h_{1}}\right) /\left((N-1) h_{1}\right)}{\sum_{j \neq i} K\left(\frac{\hat{V}_{1 i}-\hat{V}_{1 j}}{h_{1}}\right) /\left((N-1) h_{1}\right)},
$$

where $K$ is a Gaussian kernel function, and the bandwidth $h_{1}=\sigma_{\hat{V}_{1}} N^{-1 / 5}$, and $\sigma_{\hat{V}_{1}}$ is a 
standard deviation of $\hat{V}_{1}$ (see Silverman (1986)). The Hessian is estimated using the third order differentiable kernel, i.e., with the bandwidth size $h_{1}=\sigma_{\hat{V}_{1}} N^{-1 / 7}$ by

$$
-H^{-1}=E\left(\sum_{m}\left(\frac{d F_{m}\left(\hat{V}_{1 i}\right)}{d \theta}\right)\left(\frac{d F_{m}\left(\hat{V}_{1 i}\right)}{d \theta}\right)^{\prime} \frac{1}{F_{m}\left(\hat{V}_{1 i}\right)}\right)^{-1} .
$$

\subsection{Endogenous explanatory variable}

The main problem in estimating the effects of migration are the endogeneity issue, as both the decision on emigration and, consequently, the receipt of remittances are not random events. Households are self-selected in sending their member(s) abroad; as well, migrants are self-selective in returning to their home countries. In addition to these emigration self-selection issues, the duration depending heterogeneity, i.e., the decision on when to migrate, could cause the biasness in estimators (Gibson et al. 2010). The selection issue of migration in our model on the job satisfaction and the migration relationship arises as only working migrant relatives in the source country can compare their current work earnings to those from migration, while workers who do not have migrant relatives cannot. Endogeneity problems also rise when there is a simultaneity issue between an individual's job dissatisfaction and migration of the family member. Close relatives of individuals who are mostly dissatisfied with wages they receive at their current jobs due to their altruistic preferences might choose to migrate and consequently to send remittances in order to help in filling this person's needs. In such way, the coefficient on differences of wage and remittances for families with current migrants might be upward biased. Modeling unobservable variables like unreported income other than wages (such as income from informal employment) can also influence individual job satisfaction. Estimating the model without controlling for such income would produce downward biased estimates on the difference of remittances and individual current wages.

There are several ways to deal with endogeneity issues. The most popular is the instrumental variable approach. To apply similar to the instrumental variable approach to our regression analysis in respect to the inter-country wage difference, we refer to the results of Blundell and Powell (2004) and Rothe (2009). They developed a semiparametric method for estimating binary response models with continuous endogenous regressor, which can be extended to semiparametric ordered response model. However, since the endogenous explanatory variable in our model has a truncated distribution (i.e., we have do not observe outside wage differences for members in non-migrant families), instead of using the ordinary least squares estimation for the first stage reduced form equation, we use Ichimura's semiparametric non-linear least squares (Ichimura 1993).

We specify our semiparametric ordered response model with an endogenous explanatory variable:

$$
\begin{aligned}
\mathrm{E}\left(Y_{m}=1 \mid X_{1}, X_{2}, X_{3}^{e}\right) & =\operatorname{Pr}\left(X_{1}+X_{2} \theta_{1}+X_{3}^{e} \theta_{2} \geq-\epsilon^{e}\right) \\
& =\operatorname{Pr}\left(Y_{m}=1 \mid V_{1}^{e} \geq-\epsilon^{e}\right),
\end{aligned}
$$

where one of explanatory variables, $X_{3}^{e}$, is endogenous and superscript $e$ in index $V_{1}$ implies that it has an endogenous variable as its argument. 
The endogenous variable $X_{3}^{e}$ is assumed to be determined by the reduced non-linear form:

$$
X_{3}^{e}=\psi\left(Z+X_{1} \alpha_{1}+X_{2} \alpha_{2}\right)+\varepsilon,
$$

where $\varepsilon$ is a stochastic error term, $\psi(\cdot)$ is an unknown function, $\alpha$ are coefficients normalized by the coefficient of excluded from the structural equation, a continuous variable of $Z,\left(Z, X_{1}, X_{2}\right)$ is a matrix of all exogenous variables, which has a full rank with probability 1 . Then by construction, we would have:

$$
E\left(\varepsilon \mid X_{1}, X_{2}, Z\right)=0 .
$$

By defining an index $V_{2}=Z+X_{1} \alpha_{1}+X_{2} \alpha_{2}$, we can rewrite the conditional expectation of outcome $Y_{k}$ as:

$$
\mathrm{E}\left(Y_{m}=1 \mid X_{1}, X_{2}, X_{3}^{e}, V_{2}\right)=\operatorname{Pr}\left(V_{1}^{e} \geq-\epsilon^{e} \mid V_{2}\right)=F_{m}\left(V_{1}^{e}, V_{2}\right),
$$

where $F_{m}(\cdot)$ is a cumulative distribution function of $Y_{m}=1$ conditioned on two indexes, $V_{1}^{e}$ and $V_{2}$. Therefore, the semiparametric ordered response model with a continuous endogenous explanatory variable can be characterized as a double index model.

We rewrite the quasi log likelihood function in the following form:

$$
\ln \mathcal{L}=\frac{1}{N} \sum_{i} \sum_{m} \pi_{i, X_{1 i}} \pi_{i, V_{2 i}} \ln \left(F_{m}\left(V_{1 i}, V_{2 i}\right)\right)
$$

where $\pi_{X}$ and $\pi_{V_{2}}$ are trimming functions on continuous variables in $\left(X_{1}, X_{2}, X_{3}^{e}\right)$, and $V_{2}$, respectively.

$V_{2}$ is estimated in the first stage by running the Semiparametric Nonlinear Least Squares of $X_{3}^{e}$ on $\left(Z, X_{1}, X_{2}\right)$. Then conditioning on the estimates of the first stage index $\hat{V}_{2}$, we can estimate functions $F_{k}\left(V_{1 i}, \hat{V}_{2 i}\right)$ by the kernel regression estimator:

$$
\hat{F}_{m}\left(\hat{V}_{1 i}, \hat{V}_{2 i}\right)=\frac{\sum_{j \neq i} Y_{m i} K\left(\frac{\hat{V}_{1 i}-\hat{V}_{1 j}}{h_{1}}\right) K\left(\frac{\hat{V}_{2 i}-\hat{V}_{2 j}}{h_{2}}\right) /\left((N-1) h_{1} h_{2}\right)}{\sum_{j \neq i} K\left(\frac{\hat{V}_{1 i}-\hat{V}_{1 j}}{h_{1}}\right) K\left(\frac{\hat{V}_{2 i}-\hat{V}_{2 j}}{h_{2}}\right) /\left((N-1) h_{1} h_{2}\right)} .
$$

The bandwidth for two-index model is chosen as $h_{1}=\sigma_{\hat{V}_{1}} N^{-1 / 6}$ and $h_{2}=\sigma_{\hat{V}_{2}} N^{-1 / 6}$, where $\sigma_{\hat{V}_{1}}$ and $\sigma_{\hat{V}_{2}}$ are standard deviations of $\hat{V}_{1}$ and $\hat{V}_{2}$, respectively. Its Hessian is estimated using the third-order differentiable kernel, with bandwidth sizes $h_{1}=\sigma_{\hat{V}_{1}}$ $N^{-1 / 8}$ and $h_{2}=\sigma_{\hat{V}_{2}} N^{-1 / 8}$, by

$$
-H^{-1}=E\left(\sum_{m}\left(\frac{d \hat{F}_{m}\left(\hat{V}_{1 i}, \hat{V}_{2 i}\right)}{d \theta}\right)\left(\frac{d \hat{F}_{m}\left(\hat{V}_{1 i}, \hat{V}_{2 i}\right)}{d \theta}\right)^{\prime} \frac{1}{\hat{F}_{m}\left(\hat{V}_{1 i}, \hat{V}_{2 i}\right)}\right)^{-1} .
$$

To confirm that this semiparametric estimation method performs well, we decided to fulfill the experiment using Monte Carlo simulations. The experimental data was generated using the following similar structure of our model:

$$
I=1\left\{2 X_{1}+X_{2}-X_{3}-X_{4}-3>0\right\},
$$




$$
\begin{aligned}
& Y_{2}= \begin{cases}2 X_{1}+X_{2}-X_{3}-X_{4}-3+\varepsilon & : I=1 \\
0 & : I=0\end{cases} \\
& Y_{1}^{*}=3 X_{2}-X_{3}+2 X_{4}+3 Y_{2}+1+\epsilon \quad: \epsilon=5^{-1 / 2}(2 \varepsilon+u), \\
& Y_{1}=1 \quad \text { if } \quad Y_{1}^{*} \leq \tau_{1} \\
& Y_{1}=2 \quad \text { if } \quad \tau_{1}<Y_{1}^{*} \leq \tau_{2} \\
& Y_{1}=3 \quad \text { if } \quad Y_{1}^{*}>\tau_{2},
\end{aligned}
$$

where all $X^{\prime} \mathbf{s}, \varepsilon$ and $u$ have independent normal distributions. Cut points $\tau^{\prime}$ s are defined using tertiles of $Y_{1}^{*}$. The sample size is 3000; the number of Monte Carlo replications is 1000 .

It is easily seen from these equations that the true semiparametric coefficients in the reduced form equation for $Y_{2}$ are $(0.5,-0.5,-0.5)^{\prime}$, and in the structural equation for $Y_{1}$ are $(-0.33,0.67,1)^{\prime}$. The mean, median, and standard deviation of distributions of parameter estimates of the reduced form equation for $Y_{2}$ from Monte Carlo simulations are $(0.5012,-0.5006,-0.5003)^{\prime},(0.5011,-0.5002,0.4990)^{\prime}$, and $(0.0315,0.0297,0.0313)^{\prime}$, respectively. The mean, the median, and standard deviations of distributions of parameter estimates of the structural equation for $Y_{1}$ are $(-0.3265,0.6793,0.9590)^{\prime},(-0.3262$, $0.6791,0.9587)^{\prime}$ and $(0.0132,0.0166,0.0507)^{\prime}$, respectively. Our Monte Carlo experiment shows that the coefficient estimates from both reduced form and structural equations estimated using the suggested semiparametric estimation methods are very close to their true values; they have both negligible biases and smaller variances.

\section{Empirical study}

\subsection{Tajikistan's case}

We have chosen the country case of Tajikistan for several reasons. Firstly, it is a transitional country which currently experiences an increasing labor migration due to high wage differences between Tajikistan and the main destination of its migrants, Russia. The average real wages in the Russian Federation in 2010 were about 8.5 times larger than those in Tajikistan. Such wage differences not only drive more people from Tajikistan to Russia, but might also increase the dissatisfaction among current workers in Tajikistan with their current wages.

Secondly, Tajikistan and Russia share the 70-year history of association in a single country, the USSR, under similar identities, cultural norms and traditions, where people use Russian as an international communication language. Such a commonly shared historical background helps to lower migration costs. Some elder generation of Tajiks still speak Russian and hold diplomas from Soviet schools and universities, which are helpful in finding jobs in Russia. They also do not need to spend additional time and money in learning Russian language. Some Tajikistan's migrants might rely on help from their older Russian friends and families, whom with they used to work, or served in the Soviet army, in finding jobs and temporary accommodations. All these factors may positively affect the elder migrants' earnings in Russia.

Furthermore, since families heavily depend on remittances ${ }^{2}$ and because of migration being seasonal in Tajikistan (where migrants return in each winter after seasonal job cuts due to the Russia's cold weather), migrant families observe perfectly the wages of their migrant relatives through either the remittances they receive or directly from migrants themselves. The World Bank reports that the size of remittances sent by Tajik 
migrants increased from one third of the country's GDP in 2009 to $42 \%$ of its GDP in 2014 ranking Tajikistan as the world's most highly dependent country on remittances (World Bank 2011, 2016). According to 2007 Living Standards Survey on Tajikistan (State Statistical Agency of Tajikistan 2007), about 27.35\% of interviewed households received remittances in last 12 months, and $29 \%$ of those households which received remittances are heavily dependent on them. Furthermore, the International Labor Organization reports that $77 \%$ of returned Tajik migrants confirmed that they plan to migrate again in the next working season (International Labor Organization 2010). Such seasonality, easy and accurate observance of migrant's earnings would help other migrant family members, who remained in Tajikistan to build their expectations on their possible earnings from migration if they joined their migrant relatives.

International migration is relatively new phenomena in Tajikistan. As a country-member of the former Soviet Union, international migration was strictly controlled and even "prohibited" by the Central Soviet Government. After the Union's collapse, this restriction was removed, thereby involving an appreciably large proportion of Tajikistan's population.

The overall labor force participation in Tajikistan is at $43 \%$ which is lower to its comparative countries' rate. The labor force participation is reducing since the collapse of the Soviet Union, especially among women (Strokova and Ajwad 2017).

\subsection{Data and variables}

As a part of the response to the recognition of current migration trends in Tajikistan, data was collected in 2007 Living Standard Survey (State Statistical Agency of Tajikistan 2007) highlighting migrants and their families. This survey includes questions on migration, education, health, labor market, housing, transfers and social assistance, subjective poverty and food security, as well as data for household's expenditure and income. There were 4860 households surveyed in Tajikistan in 2007; 1170 households, or $24 \%$, had migrants in last 12 months.

We look at the reported overall individual satisfaction from current primary jobs in Tajikistan. The survey asks a question "Overall how satisfied are with your job?". The answers are recorded for those who were present in the household during the survey as "very satisfied," "satisfied," "neither satisfied nor dissatisfied," "dissatisfied," and "very dissatisfied." Because few observations were reported at extreme values, we put two first answer categories ("very satisfied" and "satisfied") together into one category and named it "satisfied", and two last categories ("dissatisfied" and "very dissatisfied") into another single category, and named it "dissatisfied". This categorical variable is used as the dependent variable in our regression analysis.

The sample size is 2901, including individuals with zero reported wages. We have not excluded them for two reasons. Firstly, working individuals, who reported their job satisfaction, work at different employers that include family owned businesses and farms. In such businesses and farms, involved family members do not necessarily receive individual wages in cash (i.e., they have zero reported individual work earnings), since they work at increasing family's total income which is common. Secondly, since employment in the informal sector is common in Tajikistan, many families have other than wages income from employment that might be not reported (Abdulloev et al. 2012). Since we 
would allow non-pecuniary effects and other non-reported income from current employment to be a part of the error term in our model, we did not exclude these observations from the sample. ${ }^{3}$

Our sample does not include people who reported their job satisfaction, but did not work in last 14 days because of work suspension, temporary workload reduction, enterprise closure or return from working abroad. Furthermore, we restricted our sample to include individuals in working ages from 15 to 64 according to the WB's recent Jobs Diagnostic Report on Tajikistan (Strokova and Ajwad 2017).

We are interested in estimating the effects of two variables on job satisfaction; that is the effect of intra-country and inter-country wage differences. ${ }^{4}$ The variable intra-country wage difference is constructed as the difference between the reported work earnings, which includes cash, bonuses, and in-kind payments, and the expected value of work earnings from the country's internal wage distribution, which are calculated using Mincer's (1970) earnings regression equation for each provinces of Tajikistan with division into rural and urban areas (totally 9 geographical areas). The variable inter-country wage difference is constructed as the difference between reported work earnings, which includes cash, bonuses, and in-kind payments received by non-migrating members of families of both returned in last 12 months and current migrants, and, the expected value of work earnings using parameters of the estimated Mincer's earnings regression equation for current migrants. The value of the variable on the inter-country wage differences for working individuals in non-migrant families is zero, since according to our economic model, they cannot observe information on wage distributions of destination countries (by other words, the spillover effects of migration are set at zeros). This selection issue is accounted for in our semiparametric model 2-IV (see the next section). Variables which were included in Mincer's earning regression equation include individual age, gender, and levels of education.

Other exogenous variables in the model of job satisfaction include dichotomous variables defining whether an individual has the highest level of education from any technical school (vocational education), whether the individual has the highest level of education from the university, whether an individual is male, whether an individual lives in the capital, whether the job is affiliated with a social security scheme (i.e., the National Social Protection Fund that is used to cover expenses on social protection of employees), whether the working place is in a fixed building, whether an individual works in the street or market. The model also includes continuous explanatory variables on individual ages, the number of children in the household, and monthly nominal per capita nonfood consumption in thousands of local currency (Somoni). Definitions of these variables are provided in Table 1.

As it was briefly discussed above, a main problem in estimating effects of migration is that the migration related variable in our model - the variable on the inter-country wage difference - is endogenous. There are several ways to deal with endogeneity issue, but the most popular is the instrumental variable approach. Brown and Leeves (2007) used migration networks to instrument the number of migrants in the household. This instrument is constructed using the community-level migration patterns. McKenzie and Rapoport (2007) suggest instead using historic networks as an instrument for migration since communities are affected by external shocks that would lead to changes in current migration patterns. While migrant networks are widely used as an instrument to the decisions on 
Table 1 Variable descriptions, ages of 15-64

\begin{tabular}{ll}
\hline Variables & Descriptions \\
\hline age & Individual's age \\
resm & $\begin{array}{l}\text { Difference between expected wages from migration and current work earnings, in thousands of } \\
\text { Somoni }\end{array}$ \\
resw & $\begin{array}{l}\text { Difference between expected intra-country wages and current work earnings, in thousands of } \\
\text { Somoni }\end{array}$ \\
ch14 & Number of children in families with age less than 15 \\
pcnf & Monthly per capita nonfood consumption, nominal in thousands of Somoni \\
meduc & Dummy variable on whether an individual holds the highest level of education from the vocational \\
school & \\
heduc & Dummy variable on whether an individual holds the highest level of education from university \\
male & Dummy variable on whether an individual is male \\
capl & Dummy variable on whether an individual lives in the capital city (Dushanbe) \\
ssec & Dummy variable on whether an individual's job is affiliated with social security scheme \\
fdpl & Dummy variable on whether an individual workplace is in a fixed building \\
smpl & Dummy variable on whether an individual workplace is in the street or market \\
netw & Network variable (excluded exogenous continuous variable)
\end{tabular}

family involvement into migration, there are other instrumental variables applied to migration such as distances to roads and main cities, and economic changes.

Since there was no migration history in Tajikistan as it was mentioned above, we used the current migration network per local communities as an excluded variable to control for endogeneity of migration in our semiparametric model. The migrant network variable at the community level is defined as a share of community's migrants in the total number of adults in that community (there are 269 communities in the sample). Adults are defined as those who are 15 years old and above. We define migration network per local community as:

$$
\operatorname{netw}_{R}=\frac{\sum_{R, h} m_{R, h}}{\sum_{R, h} n_{R, h}^{a d}},
$$

where netw is network variable defined for each community $R, m_{R, h}$ is a number of migrants in household $h$ in the community $R$, and, $n_{R, h}^{a d}$ is a number of adults in household $h$ in the community $R$. Since this variable is defined per community level, it is exogenous to individual decisions.

Table 2 reports summary statistics of variables for three separate groups based on reported job satisfaction: dissatisfied, neither satisfied nor dissatisfied, and satisfied. Migrant families are defined as those who have current migrants abroad or migrants who returned during last 12 months. There are 234 people who reported being dissatisfied from their jobs: 62 of them have migrant relatives and 172 people do not have. Six hundred forty-one people reported being neither satisfied nor dissatisfied from their jobs: 151 of them live in families with migrants and 490 people live in families without migrants. A larger number of people, 2026, are in the group who reported being satisfied from their jobs, out of whom 427 people have migrant relatives, and 1599 people do not have migrant relatives. 


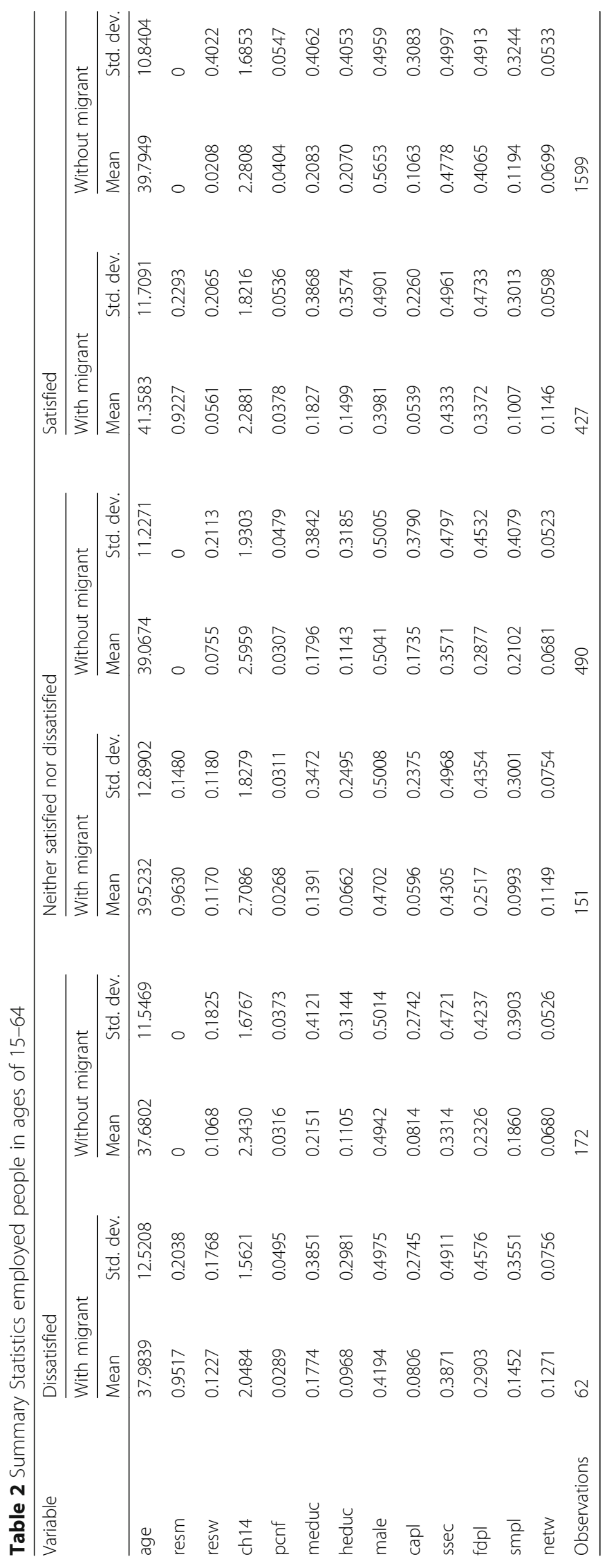


Table 2 shows that individually reported job satisfaction increases with age (age). This result is consistent with findings of Hamermesh (1977) and is probably due to decreasing worker's uncertainty about her future wage distribution. Higher dissatisfaction at younger ages might imply that, firstly, the people do not develop job-specific human capital; consequently, they are less paid relatively to elder workers. With smaller wages, younger workers are more likely being dissatisfied from their jobs than elder workers. It also might be because of the younger workers' mismatch with their current jobs. Since mismatch leads to lower wages, we can hypothesize again that younger workers exhibit higher dissatisfaction relatively to elder workers. There are differences in age means between individuals living in families with and without migrants in the all sample: those people who have migrant relatives are older than their cohorts in the same job satisfaction category. This is not surprising if one takes into account the fact that migrants in Tajikistan are predominantly young men, and because of their absence, the mean age of migrant family members increases.

The variable intra-country wage difference (resw) is increasing with the job dissatisfaction. Since this variable is constructed as difference between expected wages that individual could receive from other similar jobs within the same province of Tajikistan, and her current wages, the increase in this variable would imply that the individual receives less than an average person with similar age and educational background does. The larger this gap, the more dissatisfied people would be with their jobs because of being underpaid. However, the variable inter-country wage difference (resm) does not show the clearly monotonic relationship with job satisfaction in descriptive statistics. Another interesting picture is that the distribution between these two variables, the inter- and intra-country wage differences, which are significantly different: the variable on inter-country wage difference is larger on mean than the intra-country wage difference. This difference is due to lower wage distribution in Tajikistan compared to migrants' earnings in their destination countries.

Number of children (ch14) in the family does not show any monotonic relationship with job satisfaction. Individuals living in families with relatively more children have reported at average being neither satisfied nor dissatisfied with their jobs. Monthly per capita nonfood consumption (pcnf) of families does not significantly differ among groups with reported dissatisfaction and neither satisfaction nor dissatisfaction. However, the satisfied group of people has a higher consumption.

The level of education from vocational schools (meduc) does not differ among satisfied and dissatisfied groups, but lower for neither satisfied nor dissatisfied group. The share of people with completed vocational education is higher in migrant than non-migrant households. The gap in shares of people with university education between those who live in households with migrants and without migrants is also notable. This observation is consistent with the fact that the families are self-selected into migration: Tajikistan's families with members with lower skills or lower levels of education chose to be involved into migration, while people with higher education, or professionals, have more opportunities to engage in "unreported" income from their formal jobs, and prefer to remain in Tajikistan (Abdulloev et al. 2012). Such access to "unreported" income by professionals might be a reason for their satisfaction from current jobs.

The gender variable (male) also differs between working individuals in families with and without migrants over groups of reported job satisfaction. Individuals who reported 
being satisfied from their current jobs are $56.5 \%$ which are men living in non-migrant families and $39.8 \%$ which are men living in families with migrants. Among those who reported being neither satisfied nor dissatisfied from their jobs are $50.4 \%$ which live in families without migrants and $47 \%$ which live in families with migrants. In the dissatisfied group, $49.4 \%$ of those who live in families without migrants are men, while $41.9 \%$ of working migrants' family members are men. This difference between working members of families without and with migrants is due to male dominance in migration in Tajikistan. A larger share of people who are neither satisfied nor dissatisfied from their current jobs live in the capital of Tajikistan ( $\mathrm{capl}$ ). The share of people living in the capital city is smaller for families with migrants over both neither satisfied nor dissatisfied and job satisfied groups, which indicates that Tajikistan's migrants are predominantly from rural areas.

Affiliation with the social security scheme (ssec) of employers increases monotonically with reported job satisfaction. People working at employers who are affiliated with social security scheme feel more "secure" about their future, post retirement pension, and receive state health benefits in cases of emergencies. The social security affiliation might also imply that workers have long-term contracts with their employers, as well as employers are being well-established companies, which increases individual job satisfaction. A larger share of people who work in the street or markets $(\mathrm{smpl})$ are in the dissatisfied group-working on streets and markets implies such work types as the self-employment with an absence of social security, or at small and "young" companies, which decrease job satisfaction.

The last variable in our list is the community level migrant networks (netw). This variable does not significantly differ across job satisfaction groups: the mean of the migrant network variable for dissatisfied group is 0.0837 , for a neither satisfied nor dissatisfied group is 0.0791 , and for a satisfied group is 0.0793 . The variable's mean, however, significantly varies between individuals living in families with and without migrants: for the dissatisfied group, the mean of the migrant network for migrant relatives is 0.1271 , while, for people without migrant relatives, it is 0.068 ; for the neither satisfied nor dissatisfied group, the mean of the variable for migrant relatives is 0.1149 , but it is lower again for people without migrant relatives and equals to 0.0681 ; finally, for the satisfied group, the corresponding means of network variable for people with and without migrant relatives are 0.1146 and 0.0699 , respectively. Such non-variation of the migrant network variable across job satisfaction groups, and its variation between people living in families with and without migrants, makes it a valid instrument for migration-related variable of our model.

In the next section, we use multivariate regression analysis in order to specify the partial marginal effects of migration on individual job satisfaction.

\subsection{Regression analysis}

Tables 3 and 4 report the results from estimating the effect of an array of the variable specified above on individual job dissatisfaction using the parametric ordered probit and semiparametric ordered response models. There are two models that are reported in each table: in the model 1, we estimate the effects of all mentioned exogenous variables except the variable on the inter-country wage difference for individuals living in families with migrants, and in the model 2, we estimate the same model as in model 1 
Table 3 Ordered probit model: estimates of job satisfaction and average partial effects on job dissatisfaction, ages of 15-64

\begin{tabular}{|c|c|c|c|c|}
\hline \multirow[t]{2}{*}{ Variables } & \multicolumn{2}{|c|}{ Job satisfaction model estimates } & \multicolumn{2}{|c|}{ Average partial effects on job dissatisfaction } \\
\hline & Model 1 & Model 2 & Model 1 & Model 2 \\
\hline age & $0.0038(0.0022)^{*}$ & $0.0043(0.0022)^{*}$ & $-0.0006(0.0003)^{*}$ & $-0.0006(0.0003)^{*}$ \\
\hline resm & & $-0.1252(0.0597) * *$ & & $0.0181(0.0087)^{* *}$ \\
\hline resw & $-0.6467(0.1639)^{* * *}$ & $-0.6196(0.1631)^{* * *}$ & $0.0937(0.0241)^{* * *}$ & $0.0897(0.0239) * * *$ \\
\hline ch14 & $-0.0196(0.0135)$ & $-0.0196(0.0135)$ & $0.0028(0.0019)$ & $0.0028(0.0019)$ \\
\hline penf & $1.5474(0.7415)^{* *}$ & $1.5446(0.7382)^{* *}$ & $-0.2243(0.1073)^{* *}$ & $-0.2236(0.1067)^{* *}$ \\
\hline meduc & $0.0304(0.0660)$ & $0.0254(0.0661)$ & $-0.0044(0.0093)$ & $-0.0036(0.0094)$ \\
\hline heduc & $0.2588(0.0819)^{* * *}$ & $0.2546(0.0819)^{* * *}$ & $-0.0329(0.0091)^{* * *}$ & $-0.0324(0.0091)^{* * *}$ \\
\hline male & $0.0857(0.0488)^{*}$ & $0.0785(0.0489)$ & $-0.0124(0.0071)^{*}$ & $-0.0114(0.0071)$ \\
\hline capl & $-0.3036(0.0768)^{* * *}$ & $-0.3152(0.0772)^{* * *}$ & $0.0516(0.0148)^{* * *}$ & $0.0538(0.0150)^{* * *}$ \\
\hline ssec & $0.1044(0.0573)^{*}$ & $0.1076(0.0574)^{*}$ & $-0.0149(0.0081)^{*}$ & $-0.0154(0.0081)^{*}$ \\
\hline fdpl & $0.1232(0.0678)^{*}$ & $0.1184(0.0679)^{*}$ & $-0.0173(0.0093)^{*}$ & $-0.0166(0.0093)^{*}$ \\
\hline smpl & $-0.1788(0.0690)^{* * *}$ & $-0.1881(0.0693)^{* * *}$ & $0.0282(0.0118)^{* *}$ & $0.0298(0.0119)^{* *}$ \\
\hline Constant-cut1 & $-1.1993(0.1100)^{* * *}$ & $-1.2152(0.1098)^{* * *}$ & & \\
\hline Constant-cut2 & $-0.2903(0.1059)^{* * *}$ & $-0.3051(0.1057)^{* * *}$ & & \\
\hline Observations & 2901 & 2901 & 2901 & 2901 \\
\hline Pseudo $R^{2}$ & 0.029 & 0.030 & & \\
\hline
\end{tabular}

Dependent variable: job satisfaction (1-“dissatisfied", 2-“neither satisfied nor dissatisfied", 3-“"satisfied"). Standard errors in parentheses, ${ }^{*} p<.10,{ }^{* *} p<.05,{ }^{* * *} p<.01$

but with the inclusion of the variable on the inter-country wage difference. Notice that we allow both intra- and inter-country wage difference variables in Model 2, since in such a way, we can estimate the effect of the inter-country wage difference at constant effect of the intra-country wage difference. We also estimated the semiparametric response model accounting for endogeneity of the variable on the inter-country wage difference, which we refer to as model 2-IV. We also report the average partial effects of all model variables on predicted individual job dissatisfaction.

Both model 1 and model 2 that were estimated using the parametric ordered probit show the positive and statistically significant correlation between individual age and job satisfaction at $90 \%$ level. Since the variable on age represents an individual experience in our model, people, who have been working a longer time with their current employer, are more satisfied. Consequently, there is a negative average partial effect of age on the probability of a working individual being dissatisfied with her job. Coefficients on the number of children in both parametric models have negative signs but are not statistically significant: more children in families requires parents to spend more time with them, while under the fixed working time framework at the majority of employers in Tajikistan, parents cannot easily choose to increase their spare time, which increases their job dissatisfaction. The monthly per capita consumption of families increases the individual job satisfaction. Since the current consumption related with wealth status, having more wealth makes people happier. The average partial effect confirms this: being wealthier decreases the probability of job dissatisfaction. Variables which define individual education are positively correlated with job satisfaction: both variables on education from vocational schools and university have positive coefficients, and 


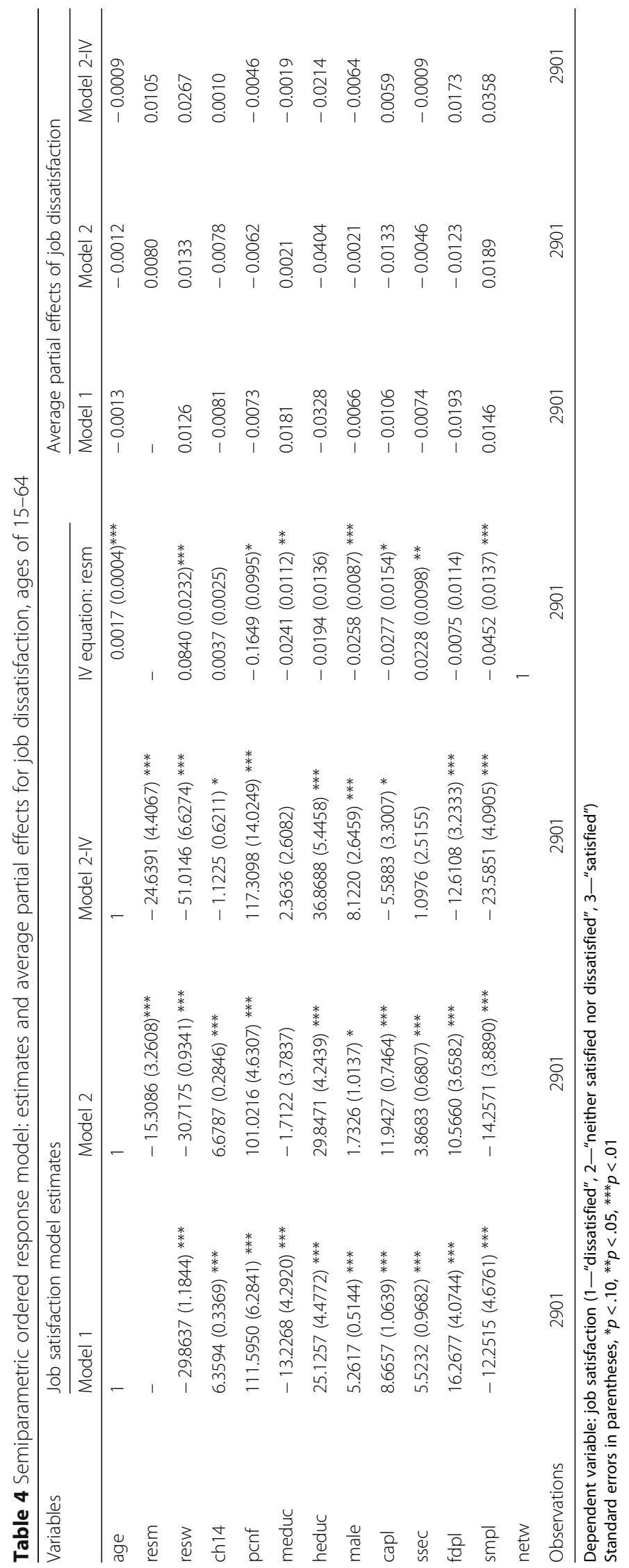


negative average partial effects on the probability of job dissatisfaction. While the estimated coefficient on the highest level of education from vocational schools is not statistically significant, the coefficient on university level of education is statistically significant at $99 \%$ level in both models. The affiliation of an employer with a social security scheme has a positive and significant at $90 \%$ level correlation with worker's job satisfaction. The coefficients on male gender dummy variable are positive and significantly different from zero at $90 \%$ level in model 1 . Living in the capital city has a significant negative impact on the individual job satisfaction in both models at $99 \%$ level. Working in fixed premises has a significantly positive impact on individual job satisfaction at $90 \%$ significance level. Unlike working in fixed premises, working in streets or markets decreases individual job satisfaction at 99\% significance level in both model specifications. The average partial effect of this variable on the probability of job dissatisfaction is positive.

Both variables, inter- and intra-country wage differences, have negative correlations with the job satisfaction in parametric models 1 and 2 . The coefficient on the intra-country wage difference is statistically significant at $99 \%$ significance level in model 1 and model 2 after inclusion of the variable on the inter-country wage difference. Such result is consistent with the job satisfaction literature: an individual job satisfaction increases with wage residuals. Since we use the reverse of residuals, the sign of its estimates is also reversed. The average partial effect of this difference is positive, which implies that the probability of job dissatisfaction increases if people receive wages lower than they could receive at similar jobs at other employers within Tajikistan. Adding the variable on the inter-country wage difference not only increases McFadden's pseudo- $R^{2}$ of the model but also shows a significant correlation of this variable with job satisfaction. The coefficient on the inter-country wage difference is negative and statistically significant at 95\% level. Its estimate in the model 2 shows that, even keeping the effect of individual intra-country wage difference constant, the difference between expected wages from migration to another country and current wages in the home country reduces significantly the job satisfaction of working migrants' relatives in the home country. The average partial effect of this variable is positive implying that an access to the information on outside wage distribution increases the probability of workers' job dissatisfaction.

Table 4 reports both estimates and average partial effects of the semiparametric ordered response models. The semiparametric estimation is based on the index representation of the model variables with normalized coefficients by coefficient of one of model's continuous variables. Since parametrically estimated models show a positive and statistically significant estimate on the age variable, we normalized other coefficients of the model using this variable. ${ }^{5}$ The positive coefficient on age allows us to consistently estimate signs of normalized coefficients of other variables. Its significance allows ratios of other coefficients with respect to it to be finite. Taking into account the positive relationship between individual age and reported job satisfaction, we expect that the signs of the semiparametric estimates of variable coefficients would reflect the right direction of correlations. Table 4 shows that variables on intra- and inter-country wage differences, monthly consumption (pcnf), education from universities (heduc), male gender (male), affiliation with social security (ssec), working in a fixed building $(f d p l)$, and working in the street or market $(s m p l)$ in the semiparametric model 1 and 
model 2 have the same sign effects on individual job satisfaction as in parametric models. Interesting to note is that the sign of living in the capital ( $\mathrm{capl}$ ) has changed (coefficient estimates of vocational education and number of children were not statistically significant), and the significance of coefficient estimates of variables has increased in semiparametrically estimated models 1 and 2, which might be due to our relaxed distributional assumptions.

Using estimates of variable coefficients, we estimate the average partial effects of the continuous explanatory variables in the semiparametric models of structural equations as the sample average of differences between the semiparametric expectation of the job dissatisfaction conditioned on the model's index where a variable of interest is increased by one keeping other variables fixed, and the semiparametric expectation of the job dissatisfaction conditioned on the index which is estimated with initial values of the variables. The average partial effects of the dichotomous variables in the semiparametric models of structural equations is also estimated as the sample average of differences of two semiparametric expectations of job dissatisfaction, where the first expectation is calculated conditionally on the index where the variable of interest is set to 1 , and where the second expectation is conditioned on the index where the same variable is set to 0 , while remaining variables in both indexes are kept fixed. Sizes of the average partial effects of variables on the probability of job dissatisfaction in all three semiparametric models are reported in last three columns in the Table 4. Their absolute values differ from those of estimated using the corresponding parametric models, i.e., model 1 and model 2. However, the sign effects of average partial effects of intra- and inter-country wage differences on the probability of job dissatisfaction are the same across all models.

In addition to semiparametric model 1 and model 2, we estimated the model 2-IV, where we controlled for endogeneity of the variable on the inter-country wage difference. The endogeneity issue of this variable rises because of the family's selection into migration. It might be also due to the possible simultaneity relationship with the job satisfaction: workers dissatisfied from their current wages might decide to send their relatives abroad in order to compensate in lower work earnings. We did not report the endogeneity correction described by Wooldridge (2010), which is based on the two stage Rivers and Vuong (1988) control function approach, where, at the first stage, the reduced form equation for endogenous variable is estimated; then, at the second stage, residuals from the reduced model should be added into the structural ordered response model in order to control for endogeneity of the variable of interest. This approach is based on the strong distributional assumption that the reduced form error term is normally distributed. We conducted tests for normality for the distribution of the first-stage residuals, Shapiro-Wilk/Shapiro-Francia and Skewness-Kurtosis tests, both tests rejected the null hypothesis. Instead, we decided to implement the endogeneity correction using the semiparametric estimation, where one does not have to make any distributional assumption on the error terms.

After controlling for the endogeneity of inter-country wage differences, the coefficient estimate of vocational education remains not significantly different from zero. The effect of the affiliation with social security scheme on job satisfaction becomes not significantly different from zero. The effects of living in the capital city (capl), number of children (ch14), and working in a fixed building ( $f d p l)$ have changed their signs to 
negative, and statistically significant at 90\% (capl and ch14) and 99\% (fdpl) levels. Other coefficients remained statistically significant from zero at the $99 \%$ significance level. The absolute size of the average partial effect of the intra-country wage difference on job dissatisfaction increases from 0.0133 to 0.0267 after we controlled for endogeneity of migration related variable. Likewise, the absolute sizes of average partial effects of male gender, and working in street or market places, increased after controlling for endogeneity. Conversely, the absolute sizes of the average partial effects of the remaining variables: individual age, monthly consumption, education levels, and affiliation with social security, are lessened after we controlled for the endogeneity of inter-country wage differences.

We also report the first stage estimates of the reduced form equation for the inter-country wage difference (resm). The coefficients of variables on age (age), intra-country wage difference (resw), male gender (male), and work in the street or markets (smpl) are statistically significant at $99 \%$ significance level. The inter-country wage difference increases in age as the elder migrants earn more based on the former Soviet experience and networks. The coefficient of the affiliation with social security scheme (ssec) is positive, and the coefficient of the vocational education (meduc) is negative; both are statistically significant at $95 \%$ level. Coefficients of living in the capital (capl) and monthly consumption (pcnf) are negative and statistically significant at $90 \%$ level. Furthermore, even though the reduced form equation is estimated using the semiparametric nonlinear model, we performed the test for weak instrumental variables basing on the $F$-statistics from the first-stage ordinary least squares estimation. The null hypothesis on the weak instrument was rejected. ${ }^{6}$

Now, we turn to the effect of the inter-country wage difference. The coefficient on this variable in the semiparametric model 2 is negative and statistically significant at 99\% significance level. After controlling for its endogeneity, the size of its coefficient increases and remains statistically significant at $99 \%$ level. The average partial effect of the inter-country wage difference on the probability of job dissatisfaction is positive and increases from 0.008 to 0.0105 after we control for its endogeneity. However, the size of its average partial effect even after controlling the endogeneity remains smaller in the absolute size than its average partial effect estimated using the parametric model 2. This result indicates that even after keeping the effect of intra-country wage differences constant, the difference between the expected wages from migration and current wages of working members among migrant relatives remaining in the source country increases their dissatisfaction from current jobs.

Such a strongly positive effect of the inter-country wage difference on the probability of job dissatisfaction indicates that it might be destructive for economic development of the source country. Since there is a positive relationship between job dissatisfaction and job quits, migrant relatives would be more likely to leave their jobs once the gap between the outside wage distribution and the intra-country wage distribution increases. Firms in the source country will be losing workers, consequently, their market competitiveness, due to increasing outmigration. Furthermore, the rigidness in wages in the source country compared to the dynamic wage increase in the destination country will be attracting more migrants to the destination country, living the source country with the shortage of labor. With limited capital endowment, the firms in less-developed countries 
cannot offer higher wages and hence would be less successful in attracting back migrants.

\section{Conclusions}

An increasing inflow of remittances is not only destroying the labor participation of remaining members of migrant families, but also increases job dissatisfactions of those who still continue working. Once working migrant relatives in the source country receive information on wage distribution in the destination country through either the size of received remittances or the information received directly from migrants, they are able to build their own expectations on the size of earnings they could receive if they migrated. If the gap between expected wages from migration and current wages increases, working relatives of migrants become dissatisfied with their current jobs.

Using both parametric and semiparametric econometric models, we find a positive significant effect of migration on the increase in the probability of job dissatisfaction of working migrants' relatives in the source country, Tajikistan. The effect remains significant even when we control for possible endogeneity of the migration-related variable. Tajikistan has a much lower wage distribution relatively to its main migration destination country, Russia, which attracts more migrants every year from Tajikistan to Russia. An accelerating wage gap between Russia and Tajikistan after the collapse of the Soviet Union not only drives more Tajikistan's population into migration but also increases the job dissatisfaction of those who left behind.

\section{Endnotes}

${ }^{1}$ See an equation (31) on the page of 1528.

${ }^{2}$ Intentional Labor Organization (2010) estimates that 57\% of remittances in Tajikistan are spent on immediate consumption and $12 \%$ and $11 \%$ of remittances are saved for short and long terms, accordingly.

${ }^{3} \mathrm{We}$, however, applied both parametric and semiparametric estimations on the sample with excluded zero wages, with the total number of observations of 2177 . The estimate for resm in the parametric model 2 is -0.1541 with standard error of 0.0733 (its marginal effect on job dissatisfaction is 0.0219). Its estimates in semiparametric model 2 and model 2-IV are -22.6412 with standard error of 16.7286 (its marginal effect on job dissatisfaction is 0.0014 ), and -15.9653 with standard error of 11.9235 (its marginal effect on job dissatisfaction is 0.0021 ), respectively.

${ }^{4}$ The appropriate term should be "salary" instead of "wage," because monthly salaries were recorded in the data. We, however, choose to stay with the "wage" term in order to avoid confusion in the discussion of the previous sections of this paper.

${ }^{5}$ In order to satisfy the identification condition C.3b in Klein and Spady (1993), we did not include other functions of age.

${ }^{6}$ We looked at whether the $F$ statistic from the first-stage OLS estimation is larger than 10 (Staiger and Stock 1997). The reported $F$ statistics is 32.23, which supports the validity of our instrument. Then, by comparing the Cragg-Donald Wald F statistic (297.69) to the Stock-Yogo weak identification test critical values (10\% maximal IV size is 16.38), we were able to reject again the null hypothesis on the weak instrument (Stock and Yogo 2005). 


\section{Acknowledgements}

I am greatly thankful to Professor Ira Gang for his precious comments and academic guidance and Professor Roger Klein for the discussions on semiparametric estimation. I would also like to thank an anonymous referee and the editor for the useful remarks.

Responsible editor: Hartmut F. Lehmann

\section{Availability of data and materials}

The datasets analyzed during the current study are available in the World Bank's microdata repository, http:// microdata.worldbank.org/index.php/catalog/72

\section{Competing interests}

The IZA Journal of Development and Migration is committed to the IZA Guiding Principles of Research Integrity. The author declares that he has observed these principles.

\section{Publisher's Note}

Springer Nature remains neutral with regard to jurisdictional claims in published maps and institutional affiliations.

Received: 19 March 2018 Accepted: 24 July 2018

Published online: 27 December 2018

\section{References}

Abdulloev I, Gang IN, Landon-Lane J (2012) Chapter 6 Migration as a Substitute for Informal Activities: Evidence from Tajikistan, in Hartmut Lehmann, Konstantinos Tatsiramos(ed.) Informal Employment in Emerging and Transition Economies (Research in Labor Economics, Volume 34) Emerald Group Publishing Limited, pp. 205-227. https:// www.emeraldinsight.com/doi/pdfplus/10.1108/S0147-9121\%282012\%290000034009

Acosta, P. (2006). Labor supply, school attendance, and remittances from international migration: the case of El Salvador. Policy Research Working Paper Series 3903, The World Bank.

Amuedo-Dorantes C, Pozo S (2006) Migration, remittances, and male and female employment patterns. Am Econ Rev 96(2):222-226

Blundell RW, Powell JL (2004) Endogeneity in semiparametric binary response models. Rev Econ Stud 71(3):655-679

Bockerman P, Ilmakunnas P (2009) Job disamenities, job satisfaction, quit intentions, and actual separations: putting the pieces together. Ind Relat 48:73-96

Bowling NA, Eschleman KJ, Wang Q (2010) A meta-analytic examination of the relationship between job satisfaction and subjective well-being. J Occup Organ Psychol 83(4):915-934

Brown RP, Leeves G (2007) Impacts of international migration and remittances on source country household incomes in small island states: Fiji and Tonga. In: Working Papers 07-13, Agricultural and Development Economics Division of the Food and Agriculture Organization of the United Nations

Cabegin EC (2006) The effect of Filipino overseas migration on the non-migrant spouse's market participation and labor supply behavior. In: IZA Discussion Paper No. 2240

Card D, Mas A, Moretti E, Saez E (2010) Inequality at work: the effect of peer salaries on job satisfaction. In: National Bureau of Economic Research, Working Paper Series \#16396

Clark AE (2001) What really matters in a job? Hedonic measurement using quit data. Labour Econ 8(2):223-242

Clark AE, Georgellis Y, Sanfey P (1998) Job satisfaction, wage changes and quits: evidence from Germany. Res Labor Econ 17:95-121

Clark AE, Oswald AJ (1996) Satisfaction and comparison income. J Public Econ 61(3):359-381

Deaton A, Muellbauer J (1981) Functional forms for labor supply and commodity demands with and without quantity restrictions. Econometrica 49(6):1521-1532

Diaz-Serrano L, Vieira JA (2005) Low pay, higher pay and job satisfaction within the European Union: empirical evidence from fourteen countries. In: IZA Discussion Papers 1558

Freeman RB (1978) Job satisfaction as an economic variable. Am Econ Rev 68(2):135-141

Gibson J, McKenzie D, Stillman S (2010) Accounting for selectivity and duration-dependent heterogeneity when estimating the impact of emigration on incomes and poverty in sending areas. In: Policy Research Working Paper Series 5268

Hamermesh DS (1977) Economic aspects of job satisfaction. In: Ashendelter OC, Oates WE (eds) Essays in labor market analysis. Israel Universities Press, Jerusalem, pp 53-72

Hamermesh DS (2001) The changing distribution of job satisfaction. J Hum Resour 36(1):1-30

Ichimura H (1993) Semiparametric least squares (SLS) and weighted SLS estimation of single-index models. J Econ 58: $71-120$

International Labor Organization (2010) Migrant remittances to Tajikistan. ILO Subregional Office for Eastern Europe and Central Asia, International Labour, Moscow

Judge TA, Watanabe S (1993) Another look at the job satisfaction-life satisfaction relationship. J Appl Psychol 78(6):939-948

Killingsworth MR (1983) Labor Supply. Cambridge University Press, Cambridge

Kim N (2007) The impact of remittances on labor supply: the case of Jamaica. In: Policy Research Working Paper Series 4120, The World Bank

Klein RW, Sherman RP (2002) Shift Restrictions and Semiparametric Estimation in Ordered Response Models. Econometrica 70(2):663-691

Klein RW, Spady RH (1993) An efficient semiparametric estimator for binary response models. Econometrica 61(2):387-421 
Kristensen N, Westergaard-Nielsen N (2006) Job satisfaction and quits - which job characteristics matters most? Danish Econ J 144(2):230-248

McKenzie D, Rapoport H (2007) Network effects and the dynamics of migration and inequality: theory and evidence from Mexico. J Dev Econ 84(1):1-24

Mincer J (1970) The distribution of labor incomes: a survey with special reference to the human capital approach. J Econ Lit 8(1):1-26

Mishra, V., Nielsen, I., Smyth, R. \& Newman, Alex, (2014), The Job Satisfaction-Life Satisfaction Relationship Revisited: Using the Lewbel Estimation Technique to Estimate Causal Effects Using Cross-Sectional Data, No. 26-14, Monash Economics Working Papers, Monash University, Department of Economics.

National Bank of Tajikistan. (2011). National Bank of Tajikistan. Retrieved September 17, 2011, from Macroeconomic Indicators. http://nbt.tj/upload/iblock/e3e/macro_ru.xls

Nguyen T, Purnamasari R (2011) Impacts of international migration and remittances on child outcomes and labor supply in Indonesia: how does gender matter? In: Policy Research Working Paper Series, No 5591, The World Bank

Rice WR, Near PJ, Hunt GR (1980) The job-satisfaction/life-satisfaction relationship: a review of empirical research. Basic Appl Soc Psychol 1(1):37-64

Rivers D, Vuong QH (1988) Limited information estimators and exogeneity tests for simultaneous probit models. J Econ 39(3):347-366

Rodriguez E, Tiongson E (2001) Temporary migration overseas and household labor supply: evidence from urban Philippines. Int Migr Rev 35(3):709-725

Rothe C (2009) Semiparametric estimation of binary response models with endogenous regressors. J Econ 153(1):51-64

Russian State Statistical Committee. (2010). Data. Retrieved December 12, 2010, from Russian State Statistical Committee. http://www.gks.ru/wps/wcm/connect/rosstat_main/rosstat/ru/statistics/publications/catalog/doc_ 1140086922125

Schroeder GE (1981) Regional living standards. In: Koropeckyj I, Schroeder GE (eds) Economics of Sovient regions. Praeger, New York, pp 118-156

Silverman BW (1986) Density estimation for statistics and data analysis. Chapman and Hall, London

Staiger D, Stock J (1997) Instrumental variables regression with weak instruments. Econometrica 65(3):557-586

State Statistical Agency of Tajikistan. (2007). Tajikistan Living Standards Survey (TLSS) 2007. Ref. TJK_2007_TLSS_v01_M. Dataset downloaded from http://microdata.worldbank.org/index.php/catalog/72

State Statistical Agency of Tajikistan. (2011). Database. Retrieved September 17, 2011, from State Statistical Agency of Tajikistan. https://stat.tj/en/database-real-sector

Statistical Committee of CIS. (2011). Average monthly nominal wage in the CIS countries, in national currency. Retrieved September 17, 2011, from Statistical Committee of CIS. http://www.cisstat.com/rus/macro/zp-2.pdf

Stock JH, Yogo M (2005) Testing for Weak Instruments in Linear IV Regression. In: Stock J, Andrews D (eds) Identification and inference for econometric models: essays in honor of Thomas J. Rothenberg. Cambridge University Press

Strokova V, Ajwad MI (2017) Tajikistan jobs diagnostic: strategic framework for jobs. In: Jobs Series, 1. from World Bank. https://openknowledge.worldbank.org/handle/10986/26029

Tait M, Padgett M, Baldwin T (1989) Job and life satisfaction: a reevaluation of the strength of the relationship and gender effects as a function of the date of the study. J Appl Psychol 74:502-507

Wooldridge J (2010) Econometric analysis of cross section and panel data. The MIT Press, Cambridge

World Bank (2011) Migration and remittances. Factbook 2011, 2nd edn Retrieved August 12, 2011, from World Bank: http://siteresources.worldbank.org/INTLAC/Resources/Factbook2011-Ebook.pdf

World Bank (2016) Migration and remittances Factbook 2016, 3rd edn Retrieved July 12, 2018, from World Bank: https:// openknowledge.worldbank.org/bitstream/handle/10986/23743/9781464803192.pdf

\section{Submit your manuscript to a SpringerOpen ${ }^{\circ}$ journal and benefit from:}

- Convenient online submission

Rigorous peer review

- Open access: articles freely available online

- High visibility within the field

- Retaining the copyright to your article

Submit your next manuscript at $\boldsymbol{\nabla}$ springeropen.com 